Check for updates

The BMJ

Cite this as: $B M J 2020 ; 371: \mathrm{m} 4780$ http://dx.doi.org/10.1136/bmj.m4780 Published: 10 December 2020

\section{Covid-19: People with history of significant allergic reactions should not receive Pfizer vaccine, says regulator}

\author{
Elisabeth Mahase
}

People who have a history of a significant allergic reaction to a vaccine, medicine, or food or who have been advised to carry an adrenaline autoinjector should not receive the Pfizer/BioNtech covid-19 vaccine, the UK's medicine regulator has said.

The Medicines and Healthcare Products Regulatory Agency (MHRA) is currently investigating two cases of anaphylactoid reactions in NHS staff who received the vaccine on 8 December. Both people-who have recovered-had a history of severe allergic reactions and carried adrenaline auto injectors. ${ }^{1}$

The MHRA has told people running sites that administer the vaccine to report any suspected adverse reactions through the yellow card scheme website $^{2}$ and to ensure that they have appropriate resuscitation facilities available.

The mRNA vaccine has so far been approved in Canada and the UK, where people over 80 who are attending hospital or being discharged, as well as healthcare workers, are being prioritised. A phase III trial found it to be as much as $95 \%$ effective 28 days after the first dose. ${ }^{3}$ The data from the trial have not yet been published or peer reviewed.

In a statement Pfizer said, "We have been advised by MHRA of two yellow card reports that may be associated with allergic reaction due to administration of the covid-19 BNT162b2 vaccine. As a precautionary measure, the MHRA has issued temporary guidance to the NHS while it conducts an investigation in order to fully understand each case and its causes. Pfizer and BioNTech are supporting the MHRA in the investigation.”

\section{Monitoring system}

Pfizer's information sheet on the vaccine states that it should not be given to people if they are allergic to the active substance or any of the other ingredients of this medicine. ${ }^{4}$ As such, people with a history of severe allergic reaction to any component of the study intervention were excluded from clinical trials. ${ }^{5}$

However, a briefing document from the US Food and Drug Administration on 10 December $^{6}$ noted that the trial data showed a "slight numerical imbalance of adverse events potentially representing allergic reactions, with more participants reporting hypersensitivity related adverse events in the vaccine group $(137(0.63 \%))$ compared with the placebo group (111 (0.51\%)).”

Experts emphasised that allergic reactions can occur with any substance but said that the quick action taken by the MHRA showed that the monitoring system was working.
Peter Openshaw, past president of the British Society for Immunology and professor of experimental medicine at Imperial College London, said, “As with all food and medications, there is a very small chance of an allergic reaction to any vaccine ... Similar to the rollout of all new vaccines and medications, this new covid-19 vaccine is being monitored closely by the MHRA.

"They will now investigate these cases in more detail to understand if the allergic reactions were linked to the vaccine or were incidental. The fact that we know so soon about these two allergic reactions and that the regulator has acted on this to issue precautionary advice shows that this monitoring system is working well."

Penny Ward, visiting professor in pharmaceutical medicine at King's College, London, said, "It is understood that the people concerned had a history of allergy severe enough to require them to carry an adrenaline autoinjector; such people would be at increased risk of an allergic reaction to novel challenge compared to the population without a history of severe allergy. These two reactions were treated, and it is understood that the people affected recovered well."

Stephen Evans, professor of pharmacoepidemiology at the London School of Hygiene \& Tropical Medicine, added, "For the general population this does not mean that they would need to be anxious about receiving the vaccination. One has to remember that even things like Marmite can cause unexpected severe allergic reactions."

Philpotts E. Don't give Pfizer Covid vaccine to patients with "significant" allergic reactions history, says MHRA. Pulse 2020 Dec 9. https://www.pulsetoday.co.uk/news/coronavirus/dont-give-pfizer-covidvaccine-to-patients-with-significant-allergic-reactions-history-gps-told/.

2 Coronavirus Yellow Card reporting site. 2020. https://coronavirus-yellowcard.mhra.gov.uk.

3 Mahase E. Covid-19: Pfizer and BioNTech submit vaccine for US authorisation. BMJ 2020;371:m4552 doi: 10.1136/bmj.m4552 pmid: 33219049

4 UK Government. Information for UK recipients on Pfizer BioNTech COVID-19 vaccine. 2020. https://assets.publishing.service.gov.uk/government/uploads/system/uploads/attachment_data/file/940566/Information_for_UK_recipients_on_Pfizer_BioNTech_COVID-19_vaccine.pdf.

5 Pfizer. A phase 1/2/3, placebo-controlled, randomized, observer-blind, dose-finding study to evaluate the safety, tolerability, immunogenicity, and efficacy of SARS-CoV-2 RNA vaccine candidates against covid-19 in healthy individuals. Nov 2020. https://pfe-pfizercom-d8-prod.s3.amazonaws.com/2020-11/C4591001_Clinical_Protocol_Nov2020.pdf.

6 US Food and Drug Administration. Vaccines and related biological products advisory committee meeting: FDA briefing document Pfizer-BioNTech covid-19. 10 Dec 2020. https://www.fda.gov/media/144245/download.

This article is made freely available for use in accordance with BMJ's website terms and conditions for the duration of the covid-19 pandemic or until otherwise determined by BMJ. You may use, download and print the article for any lawful, non-commercial purpose (including text and data mining) provided that all copyright notices and trade marks are retained. 